\title{
Estradiol induces JNK-dependent apoptosis in glioblastoma cells
}

\author{
NEDRET ALTIOK ${ }^{1}$, MELIKE ERSOZ $^{2}$ and MERAL KOYUTURK ${ }^{3}$ \\ ${ }^{1}$ Department of Pharmacology, Yeni Yuzyil University School of Medicine; ${ }^{2}$ Institute of Medical Sciences \\ and ${ }^{3}$ Department of Histology and Embryology of Istanbul Science/Bilim University, Istanbul, Turkey
}

Received May 19, 2011; Accepted August 9, 2011

DOI: $10.3892 / \mathrm{ol} .2011 .385$

\begin{abstract}
Estrogens exert multiple regulatory actions on cellular events in a variety of tissues including the brain. In the present study, the signaling mechanisms of the concentration-dependent effects of $17-\beta$-estradiol (estradiol) on glioblastoma cells were investigated. Cell viability was evaluated by the trypan blue exclusion assay. Cell growth and kinase activities were evaluated by immunocytochemistry and Western blotting. The results showed that high concentrations of estradiol inhibit growth and induce apoptosis in C6 rat glioma and T98G human glioblastoma cells. The blockade of the c-jun $\mathrm{NH}_{2}$-terminal kinase (JNK) signaling pathway prevented these effects of estradiol, indicating the critical role of the JNK/c-jun signaling cascade in glioblastoma cell growth inhibition and cell death in response to high concentrations of estradiol. Collectively, these findings highlight the potential of new discoveries in sensitizing estrogen-sensitive tumors to chemotherapeutic drugs, and may lead to the development of new JNK-based effective therapies.
\end{abstract}

\section{Introduction}

Glioblastomas are the most common and aggressive primary brain tumors in adults, with uncontrolled proliferation, invasiveness and resistance to conventional and novel therapeutic approaches $(1,2)$. Thus, new and effective treatments are required, particularly to overcome the drug resistance in these tumors (3).

Evidence suggests that estrogen affects glioblastoma cells, since certain glioblastomas express estrogen receptors (ERs) (4,5). Furthermore, the ER-modulator tamoxifen has been shown to inhibit the growth of certain glioblastomas (6-8). In an earlier study, we showed that high

Correspondence to: Dr Nedret Altiok, Yeni Yuzyil University School of Medicine, Department of Pharmacology, Yilanli Ayazma Caddesi No. 26, Cevizlibag-Topkapi, Istanbul, Turkey

E-mail: naltiok@superonline.com

Present address: ${ }^{3}$ Cerrahpasa Medical Faculty, Department of Histology and Embryology, Istanbul, Turkey

Key words: apoptosis, JNK/c-Jun, cancer therapy, estradiol, glioblastoma concentrations of 17- $\beta$-estradiol (estradiol) induce apoptosis in the estrogen-dependent human breast cancer cell line MCF-7, but not in the ER-negative human breast cancer cell line MDA-MB 231, under low growth-stimulated conditions (9). Given that estradiol may induce cell growth or cell death under differing conditions depending on the concentration of estradiol and the expression of ERs in the brain and other tissues (10-12), we analyzed the effects of high concentrations of estradiol in the rat glioma C6 and the human glioblastoma multiforme $\mathrm{T} 98 \mathrm{G}$ cells.

In line with our previous study showing the ability of c-Jun N-terminal kinase (JNK) to mediate estradiol's antiproliferative and apoptotic effects in breast cancer cells (9), we applied the same experimental paradigm and observed a dose-related effect of estradiol on glioblastoma cell survival. The aim was to investigate the signaling mechanisms of the concentration-dependent effects of $17-\beta$-estradiol on glioblastoma cells.

\section{Materials and methods}

Reagents. SP600125, PD98059 and SB203580 were purchased from Calbiochem (San Diego, CA, USA). Anti-phospho-c-jun, anti-c-jun and anti-phospho-ERK1/2 antibodies were purchased from New England Biolabs (Ipswich, MA, USA). Anti-JNK1 and anti-rabbit alkaline phosphatase conjugated antibodies from Santa Cruz Biotechnology Inc. (Santa Cruz, CA, USA). Anti-BrdU and anti-PCNA monoclonal antibodies were purchased from Zymed Laboratories, USA. Anti-rabbit and anti-mouse biotin conjugated antibodies, streptavidin, biotinylated horseradish peroxidase (HRP) and aminoethylcarbazole (AEC) were purchased from Dako (Denmark). Cell culture media were purchased from Gibco, and antibiotics and all the other reagents from Sigma Chemical Co (St. Louis, MO, USA).

Cell culture. C6 rat glioma and T98G glioblastoma cells were obtained from the American Type Culture Collection (Manassas, VA, USA). Cells were maintained in Dulbecco's modified Eagle's medium/F12 medium supplemented with $5 \%$ heat inactivated fetal bovine serum (FBS) and antibiotics (100 U/ml penicillin $\mathrm{G}, 100 \mu \mathrm{g} / \mathrm{ml}$ streptomycin) at $37^{\circ} \mathrm{C}$ in $5 \%$ $\mathrm{CO}_{2}$ and $95 \%$ air in a humidified incubator. For experiments performed under low growth-stimulated conditions, cells were switched to $2 \%$ FBS-containing medium (to limit exposure to exogenous estrogen) $8 \mathrm{~h}$ prior to the addition of drugs, and incubations continued as indicated for each experiment. 
Cell viability. Cells were treated as described and detached with $0.25 \%$ trypsin in Hank's balanced salt solution and counted in a hemocytometer. Cytotoxicity was determined with $0.2 \%$ trypan blue solution and the unstained viable cells were microscopically distinguished from the blue-stained damaged cells.

Immunocytochemistry. Cells grown on coverslips were incubated with drugs as indicated. Coverslips were washed with phosphate-buffered saline (PBS) and fixed with methanol for 5 min at $-20^{\circ} \mathrm{C}$. To avoid non-specific immunostaining, cells were incubated with $3 \%$ bovine serum albumin (BSA) in PBS for $1 \mathrm{~h}$ at room temperature. Following PBS washes, primary antibodies specific to the indicated proteins were applied to coverslips overnight at $4^{\circ} \mathrm{C}$. Following washing with PBS, biotinylated secondary antibodies and HRP conjugated streptavidin were applied. Sections were developed by using AEC as the substrate. Images were captured using an Olympus BX-50 brightfield microscope.

Cell lysis. Following treatment, cells grown in culture dishes were washed once with ice-cold PBS and lysed in a buffer containing $20 \mathrm{mM}$ Tris- $\mathrm{Cl}$ (pH 7.4), $150 \mathrm{mM} \mathrm{NaCl}, 1 \mathrm{mM}$ EDTA, $1 \%$ Triton X-100, $2 \mathrm{mM}$ sodium orthovanadate, $10 \mathrm{mM} \beta$-glycerophosphate, $10 \mathrm{mM} \mathrm{NaF}, 0.5 \mathrm{mM}$ PMSF, $2 \mu \mathrm{g} /$ $\mathrm{ml}$ aprotinin and $2 \mu \mathrm{g} / \mathrm{ml}$ leupeptin. Insoluble material was removed by centrifugation at $13,000 \mathrm{x}$ g for $10 \mathrm{~min}$ at $4^{\circ} \mathrm{C}$.

Western blot analysis. An equivalent volume of 2X SDS-sample buffer was added to cell lysates and boiled for $5 \mathrm{~min}$. The supernatants were subjected to electrophoresis on SDS-PAGE gels and transferred to nitrocellulose membranes by using a Bio-Rad apparatus (Bio-Rad, Hercules, CA, USA). Membranes were blocked for $1 \mathrm{~h}$ at room temperature in PBS containing 3\% non-fat dried milk and probed overnight at $4^{\circ} \mathrm{C}$ with primary antibodies. The immobilized proteins were detected by using alkaline phosphatase conjugated secondary antibodies in PBS containing 3\% milk. Following washing with PBS, bands were visualized by using BCIP/NBT as substrates.

Cell proliferation. Cell proliferation was determined using bromodeoxyuridine (BrdU) labeling and by detecting the expression of the proliferating cell nuclear antigen (PCNA) by an immunocytochemical method. In vivo labeling was carried out by administering 5-bromo-2'-deoxyuridine $(1 \mathrm{mM})$ to $50 \%$ confluent cells on coverslips for $1 \mathrm{~h}$ at $37^{\circ} \mathrm{C}$. Following PBS washes, coverslips were fixed with methanol for $5 \mathrm{~min}$, and DNA was denatured by incubating slides with $2 \mathrm{~N} \mathrm{HCl}$ in $\mathrm{H}_{2} \mathrm{O}$ at $37^{\circ} \mathrm{C}$ for $30 \mathrm{~min}$. Following neutralization with $0.1 \mathrm{M}$ boric acid ( $\mathrm{pH} 8.5)$ for $10 \mathrm{~min}$, cells were incubated for $1 \mathrm{~h}$ at $37^{\circ} \mathrm{C}$ with a monoclonal anti-BrdU antibody, followed by detection using a streptavidin-biotin-peroxidase complex and staining with AEC. Images were captured using an Olympus BX-50 brightfield microscope.

\section{Results}

Estradiol decreased cell viability. The effect of estradiol on cell viability was tested in the rat and human glioblastoma cell lines, C6 and T98G, respectively, by the trypan blue exclusion

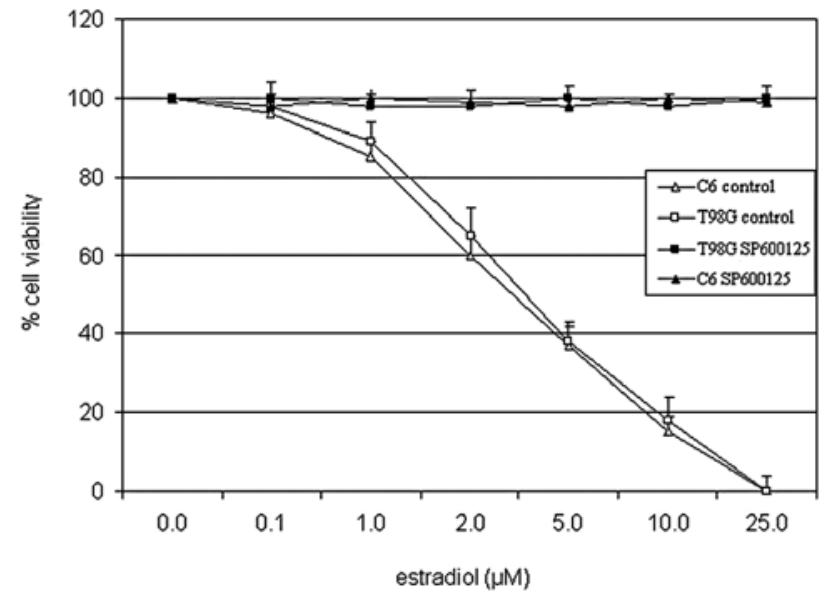

Figure 1. Estradiol induced cytotoxicity in C6 and T98G cells. Cells were pretreated with JNK inhibitor, SP600125 $(20 \mu \mathrm{M})$ or vehicle (control) under low growth-stimulated conditions for $30 \mathrm{~min}$ prior to treatment with increasing concentrations of estradiol for $24 \mathrm{~h}$. Viable cells were detected by the trypan blue exclusion assay. Data points are an average of the results obtained from three separate experiments.

assay. In the range of 0.1-25 $\mu \mathrm{M}$, estradiol decreased cell viability in a concentration-dependent manner (approximate IC50: $3.5 \mu \mathrm{M}$ in C6 and $3.8 \mu \mathrm{M}$ in T98G cells) at $24 \mathrm{~h}$ under low growth-stimulated conditions ( $2 \% \mathrm{FBS}$ ) in vehicle-treated control cells (Fig. 1). Estradiol was not cytotoxic in these cells under high growth-stimulated conditions (10\% FBS) (data not shown).

Previously, we showed that the cytotoxic effect of estradiol on MCF-7 cells was mediated by the JNK signaling pathway (9). The pharmacological inhibitors of MAPK signaling pathways, PD098059 $(20 \mu \mathrm{M})$ and SB203580 $(20 \mu \mathrm{M})$, inhibitors of MEK1 and $\mathrm{p} 38$ kinase, respectively, did not affect estradiol-induced cell death (data not shown), excluding the role of the MEK1/Erk1/2 or p38 kinase pathways. On the other hand, blockade of JNK activity by $20 \mu \mathrm{M}$ of the selective inhibitor of JNK1/2/3, SP600125 (13), completely reversed cell death induced by higher concentrations of estradiol under low growth-stimulated conditions (Fig. 1). These data indicated that the JNK pathway plays a significant role in estradiol-induced cell death in the two glioblastoma cell lines.

Estradiol inhibited cell growth. We tested whether estradiol affects cell growth in C6 and T98G cells under low growth-stimulated conditions, where it exerts its cytotoxic effect. Although low nanomolar concentrations of estradiol were found to be ineffective, whereas high concentrations of estradiol induced growth arrest and cell death in C6 and T98G cells. We also showed that suppression of the activation of JNKs completely eliminates estradiol-induced apoptosis and growth inhibition, suggesting a role for JNKs in estradiolinduced cytotoxicity in glioblastoma cells. Treatment with estradiol $(0.1-25 \mu \mathrm{M})$ dose-dependently inhibited the proliferation of $\mathrm{C} 6$ and $\mathrm{T} 98 \mathrm{G}$ cells within $18 \mathrm{~h}$ as detected by $\mathrm{BrdU}$ incorporation and PCNA expression assays (Fig. 2). Similar concentrations of estradiol did not show any inhibition of proliferation of $\mathrm{C} 6$ and $\mathrm{T} 98 \mathrm{G}$ cells under growth-stimulated conditions (10\% FBS) (data not shown). Treatment with 


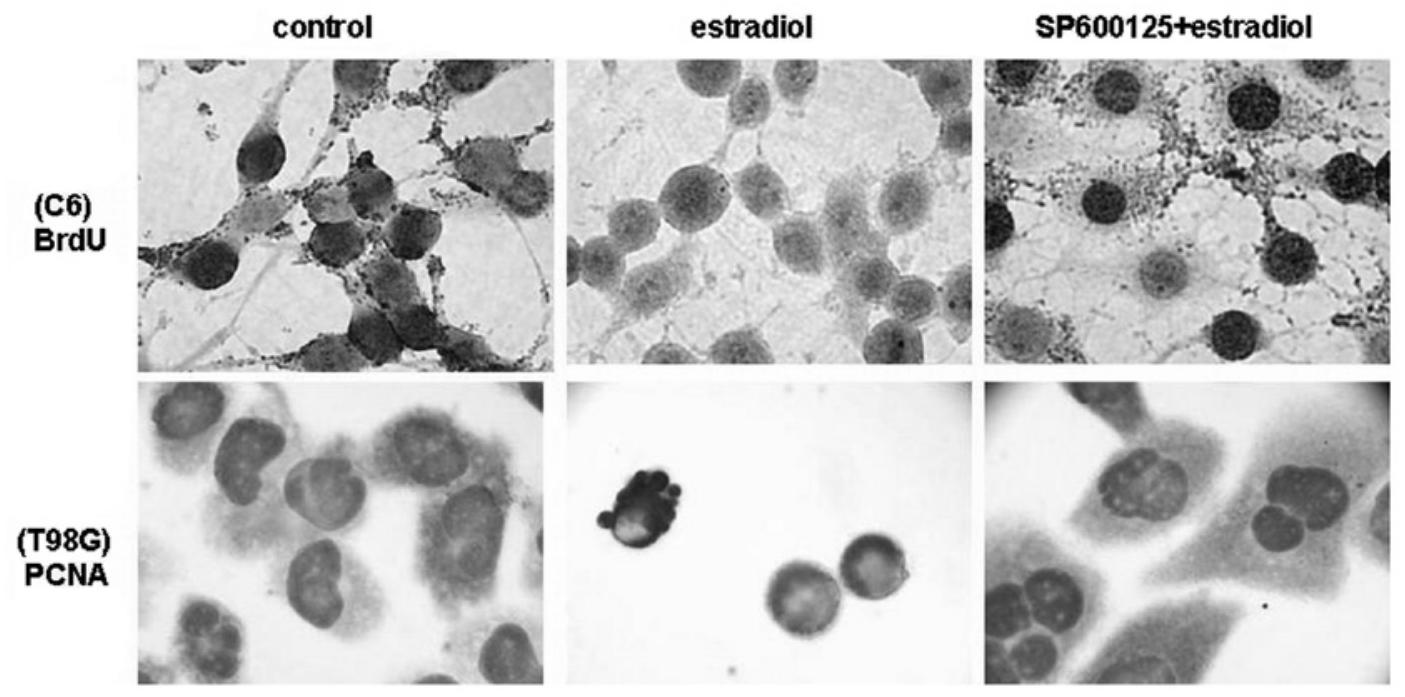

Figure 2. Estradiol inhibited cell proliferation in C6 and T98G cells. Cells were pretreated with SP600125 (20 $\mu$ M) or vehicle (control) for 30 min, and incubated for $18 \mathrm{~h}$ in the presence or absence of estradiol $(20 \mu \mathrm{M})$ under low growth-stimulated conditions. BrdU incorporation in C6 cells (upper panel) and PCNA expression analysis in T98G cells (lower panel) were carried out. Images were captured using a brightfield microscope at a magnification of x600.

estradiol $(20 \mu \mathrm{M})$ for $18 \mathrm{~h}$ resulted in almost total reduction in the proliferation of $\mathrm{C} 6$ and T98G cells as compared with levels in vehicle-treated control cells under low growthstimulated conditions, as shown by BrdU incorporation and PCNA expression assays (Fig. 2). When cells were pretreated with $20 \mu \mathrm{M}$ JNK inhibitor SP600125, the growth inhibitory effect of estradiol was completely blocked. However, the MAPK inhibitors PD98059 and SB203580 were not effective on cell growth in the presence or absence of estradiol, similar to their lack of effect on cell death (data not shown). These data suggest that high concentrations of estradiol inhibit the cell growth of C6 and T98G cells via JNK activation.

Estradiol induced JNK activation. Since SP600125, a selective inhibitor for JNKs, alleviated the growth inhibitory and apoptotic effects of high concentrations of estradiol, we examined the activity of JNKs in the estradiol-treated glioblastoma cell lines C6 and T98G, by measuring the level of endogenous phosphorylated c-jun by immunocytochemistry (Fig. 3A) and Western blotting (Fig. 3B). Exposure to estradiol $(20 \mu \mathrm{M})$ for $18 \mathrm{~h}$ in low growth-stimulated media increased the level of phosphorylated c-jun at Ser 73 in C6 and T98G cells as shown by staining in the nuclei (Fig. 3A). We then performed Western blot analysis of C6 and T98G cell extracts to further examine the phosphorylated c-jun levels in response to estradiol treatment. Cell extracts were prepared and subjected to Western blotting with an antibody that recognizes phosphorylated c-jun at Ser 73 and junD at Ser 100. Consistent with the immunocytochemical data presented in Fig. 3A, the phosphorylation of c-jun increased following $18 \mathrm{~h}$ of estradiol $(20 \mu \mathrm{M})$ treatment in C6 and T98G cells under low growth-stimulated conditions (Fig. 3B). The pretreatment of the cells with SP600125 $(20 \mu \mathrm{M})$ completely eliminated the phosphorylation of c-jun by estradiol in immunocytochemistry (Fig. 3A) and Western blot (Fig. 3B) assays. We also performed Western blotting with a native antibody reactive with JNK1, JNK2 and JNK3, and found that the level of endogenous JNK isoforms remained constant with these treatments (Fig. 3B). These studies suggest that induction of cell death and growth inhibition by high concentrations of estradiol in glioblastoma cells is mediated by $\mathrm{JNK}$ activation.

\section{Discussion}

We have previously shown that high concentrations of estradiol, under low growth-stimulated conditions, inhibit cell proliferation and increase apoptosis in ER-positive breast cancer cells through the sustained activation of the JNK pathway (9), underlying the basis for the antitumor effects of high-dose estrogen therapy in postmenopausal women approximately 40 years ago (12). Recently, high concentrations of estradiol were shown to trigger apoptosis in adrenal carcinoma cells (14), indicating that the mechanisms of these cytotoxic effects of estradiol remain to be further elucidated.

Glioblastomas are the most aggressive type of brain tumors, with a poor prognosis and a limited response to chemotherapy and other therapeutic strategies $(1,2)$. Failure of therapy arises from the resistance of tumor cells to therapy-induced apoptosis (3); therefore, new drugs targeting alternative pathways are required.

In the present study, estradiol was found to induce apoptosis and suppress cell growth in a concentration- and timedependent manner in C6 glioma and T98G glioblastoma cells. Both of these cells express ERs $(4,5)$, suggesting that estradiol may affect glioblastoma cells by regulating the ER-mediated transcription of genes involved in cell survival and death.

Estradiol, the predominant form of estrogen, mediates its effects via the activation of intracellular signaling pathways on neurons and glial cells $(15,16)$. Estradiol also exerts non-genomic rapid actions via a direct interaction of estradiol with plasma-associated ERs and the activation of second messenger pathways $(17,18)$. The late and sustained effects of estradiol described in this study suggest that non-genomic rapid actions of estradiol are not involved.

We further showed that JNK is activated following treatment with estradiol, which is accompanied by an increase 
A

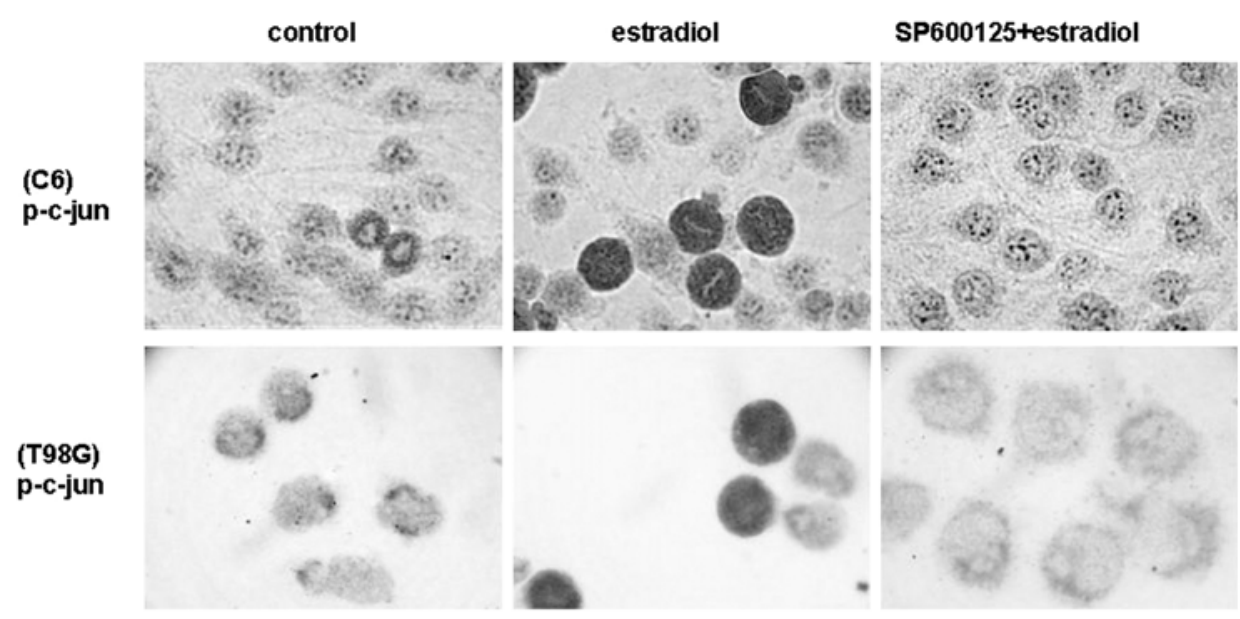

B

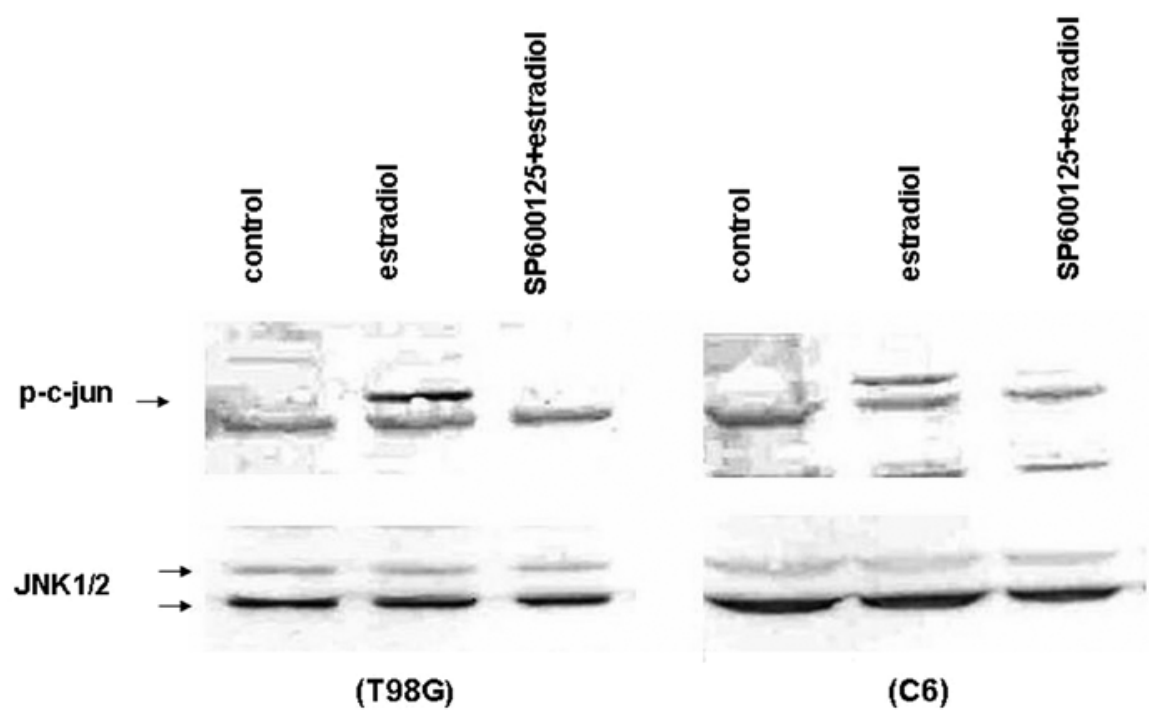

Figure 3. Estradiol induced JNK activation. (A) Immunocytochemical analysis showing c-jun phosphorylation (p-c-Jun) in C6 cells (upper panel) and in T98G cells (lower panel) pretreated with $20 \mu \mathrm{M} \mathrm{SP} 600125$ or vehicle (control) for $30 \mathrm{~min}$, and incubated with $20 \mu \mathrm{M}$ estradiol for $18 \mathrm{~h}$ under low growth-stimulated conditions. Phosphorylation of c-jun was visualized by anti-phosphorylated-c-jun antibody. Cells were visualized by using biotinylated secondary antibody, streptavidin/HRP and AEC chromogen. Images were captured using a brightfield microscope at a magnification of x600. (B) Western blot analysis for the level of phosphorylated c-Jun (p-c-Jun) in C6 cells (right panel) and in T98G cells (left panel) pretreated with $20 \mu$ M SP600125 or vehicle (control) for 30 min, and incubated with $20 \mu \mathrm{M}$ estradiol, for $18 \mathrm{~h}$ under low growth-stimulated conditions. Cell lysates were separated by 10\% SDS-PAGE, and Western blotted with polyclonal antibody against the phosphorylated form of c-jun (upper panels). The corresponding native proteins of JNKs from the same lysates were blotted in separate membranes and shown in the lower panels. The blots were then visualized by using alkaline phosphatase conjugated secondary antibodies and BCIP/NBT as substrates.

in c-Jun S63/73 phosphorylation leading to the well-known increased activity of the c-Jun transactivation domain. These results suggest that the apoptotic death of glioblastoma cells induced by estradiol requires JNK signaling, but whether c-Jun or another transcription factor is a critical JNK effector in this response remains to be clarified.

JNKs belong to the superfamily of mitogen-activated protein kinases and are encoded by three genes (JNK1, JNK2 and JNK3), which are differentially spliced to a total of 10 isoforms (19). A combined siRNA knockdown of the three JNK genes provides substantial neuroprotection, whereas silencing of the individual JNKs does not protect, suggesting that any one of the three JNKs is capable of mediating apoptosis (20). This observation may explain the reason for the knockdown of JNK1 using siRNA failing to protect the glioblastoma cells from the apoptotic effect of estradiol in our experiments (data not shown). However, the pharmacological inhibition of the three JNK isoforms by SP600125 resulted in marked protection from the cytotoxic action of estradiol.

The role of JNKs in cancer is indicated by their ability to cause tumor suppression and induce apoptosis in response to certain anti-cancer drugs (21-24). However, this increased responsiveness to chemotherapeutics is attenuated in advanced tumors, where JNK signaling is impaired, rendering the cells refractory to chemotherapy (22-24). Recently, it has been reported that MEKK1 is one of the 50 genes containing somatic missense and nonsense mutations in various tumors (25), and MEKK1 is required for JNK activation and induction of apoptosis by drugs causing cytoskeletal disruption, indicating the importance of the MEKK1/JNK-dependent apoptotic pathway in carcinogenesis (26). Therefore, due to the acquired resistance to chemotherapeutic drugs, investigation 
of new targets with the potential for discovering new cancerspecific treatments is increasingly significant.

Consistent with our previous findings in breast cancer cells (9), in this study we provide new evidence that JNK activation in response to high concentrations of estradiol plays a proapoptotic role in glioblastoma cells via growth inhibition and subsequent cell death of estrogen-depleted cells. In conclusion, new therapies that up-regulate JNK activity may prove efficacious in overcoming drug resistance in glioblastomas and other ER-positive tumors.

\section{Acknowledgements}

This study has been funded in part by the Istanbul Science University Institute of Medical Sciences.

\section{References}

1. Minniti G, Muni R, Lanzetta G, Marchetti P and Enrici RM Chemotherapy for glioblastoma: current treatment and future perspectives for cytotoxic and targeted agents. Anticancer Res 29: 5171-5184, 2009.

2. Quick A, Patel D, Hadziahmetovic M, Chakravarti A and Mehta M: Current therapeutic paradigms in glioblastoma. Rev Recent Clin Trials 5: 14-27, 2010.

3. Lino M and Merlo A: Translating biology into clinic: the case of glioblastoma. Curr Opin Cell Biol 21: 311-316, 2009.

4. Yague JG, Lavaque E, Carretero J, Azcoitia I and Garcia-Segura LM: Aromatase, the enzyme responsible for estrogen biosynthesis, is expressed by human and rat glioblastomas. Neurosci Lett 368: 279-284, 2004.

5. Sribnick EA, Ray SK and Banik NL: Estrogen prevents glutamateinduced apoptosis in C6 glioma cells by a receptor-mediated mechanism. Neuroscience 137: 197-209, 2006.

6. Hui AM, Zhang W, Chen W, Xi D, Purow B, Friedman GC and Fine HA: Agents with selective estrogen receptor (ER) modulator activity induce apoptosis in vitro and in vivo in ER-negative glioma cells. Cancer Res 64: 9115-9123, 2004.

7. Moodbidri MS and Shirsat NV: Activated JNK brings about accelerated apoptosis of Bcl-2-overexpressing C6 glioma cells on treatment with tamoxifen. J Neurochem 92: 1-9, 2005.

8. Tian F, Wu H, Li Z, Wang N, Huang J, Li C and Xie F: Activated PKCalpha/ERK1/2 signaling inhibits tamoxifen-induced apoptosis in C6 cells. Cancer Invest 27: 802-808, 2009.

9. Altiok N, Koyuturk M and Altiok S: JNK pathway regulates estradiol-induced apoptosis in hormone-dependent human breast cancer cells. Breast Cancer Res Treat 105: 247-254, 2007.

10. McCarthy MM: The two faces of estradiol: effects on the developing brain. Neuroscientist 15: 599-610, 2009.

11. Waters EM and Simerly RB: Estrogen induces caspase-dependent cell death during hypothalamic development. J Neurosci 29: 9714-9718, 2009.

12. Lewis-Wambi JS and Jordan VC: Estrogen regulation of apoptosis: how can one hormone stimulate and inhibit? Breast Cancer Res 11: 206, 2009.
13. Bennett BL, Sasaki DT, Murray BW, O'Leary EC, Sakata ST, $\mathrm{Xu}$ W, Leisten JC, Motiwala A, Pierce S, Satoh Y, Bhagwat SS, Manning AM and Anderson DW: SP600125, an anthrapyrazolone inhibitor of Jun N-terminal kinase. Proc Natl Acad Sci USA 98: 13681-13686, 2001.

14. Prieto LM, Brown JW, Perez-Stable C and Fishman LM: High dose 17 beta-estradiol and the alpha-estrogen agonist PPT trigger apoptosis in human adrenal carcinoma cells but the beta-estrogen agonist DPN does not. Horm Metab Res 40: 311-314, 2008.

15. Pozzi S, Benedusi V, Maggi A and Vegeto E: Estrogen action in neuroprotection and brain inflammation. Ann N Y Acad Sci 1089: 302-323, 2006.

16. Morissette M, Le Saux M, D'Astous M, Jourdain S, Al Sweidi S, Morin N, Estrada-Camerana E, Mendez P, Garcia-Segura LM and Di Paolo T: Contribution of estrogen receptors alpha and beta to the effects of estradiol in the brain. J Steroid Biochem Mol Biol 108: 327-338, 2008.

17. Raz L, Khan MM, Mahesh VB, Vadlamudi RK and Brann DW: Rapid estrogen signaling in the brain. Neurosignals 16: 140-153, 2008.

18. Levin ER: Plasma membrane estrogen receptors. Trends Endocrinol Metab 20: 477-482, 2009.

19. Waetzig V and Herdegen T: Context-specific inhibition of JNKs: overcoming the dilemma of protection and damage. Trends Pharmacol Sci 26: 455-461, 2005.

20. Björkblom B, Vainio JC, Hongisto V, Herdegen T, Courtney MJ and Coffey ET: All JNKs can kill, but nuclear localization is critical for neuronal death. J Biol Chem 283: 19704-19713, 2008.

21. Mhaidat NM, Zhang XD, Jiang CC and Hersey P: Docetaxelinduced apoptosis of human melanoma is mediated by activation of c-Jun NH2-terminal kinase and inhibited by the mitogenactivated protein kinase extracellular signal-regulated kinase 1/2 pathway. Clin Cancer Res 13: 1308-1314, 2007.

22. Kolomeichuk SN, Terrano DT, Lyle CS, Sabapathy K and Chambers TC: Distinct signaling pathways of microtubule inhibitors - vinblastine and Taxol induce JNK-dependent cell death but through AP-1-dependent and AP-1-independent mechanisms, respectively. FEBS J 275: 1889-1899, 2008.

23. Lagadinou ED, Ziros PG, Tsopra OA, Dimas K, Kokkinou D, Thanopoulou E, Karakantza M, Pantazis P, Spyridonidis A and Zoumbos NC: c-Jun N-terminal kinase activation failure is a new mechanism of anthracycline resistance in acute myeloid leukemia. Leukemia 22: 1899-1908, 2008.

24. Zerp SF, Stoter R, Kuipers G, Yang D, Lippman ME, van Blitterswijk WJ, Bartelink H, Rooswinkel R, Lafleur V and Verheij M: AT-101, a small molecule inhibitor of anti-apoptotic Bcl-2 family members, activates the SAPK/JNK pathway and enhances radiation-induced apoptosis. Radiat Oncol 4: 47, 2009.

25. Kan Z, Jaiswal BS, Stinson J, Janakiraman V, Bhatt D, Stern HM, Yue P, Haverty PM, Bourgon R, Zheng J, Moorhead M, Chaudhuri S, Tomsho LP, Peters BA, Pujara K, Cordes S, Davis DP, Carlton VE, Yuan W, Li L, Wang W, Eigenbrot C, Kaminker JS, Eberhard DA, Waring P, Schuster SC, Modrusan Z, Zhang Z, Stokoe D, de Sauvage FJ, Faham M and Seshagiri S: Diverse somatic mutation patterns and pathway alterations in human cancers. Nature 466: 869-73, 2010.

26. Tricker E, Arvand A, Kwan R, Chen GY, Gallagher E and Cheng G. Apoptosis induced by cytoskeletal disruption requires distinct domains of MEKK1. PLoS One 6: e17310, 2011. 